\title{
Uma reflexão epistemológica sobre o status científico da administração sob a ótica dos critérios de demarcação científica de Popper, Kuhn e Lakatos
}

\author{
An Epistemological Reflection on the Scientific Status of Administration Under \\ the View of the Scientific Demarcation Criteria of Popper, Kuhn, and Lakatos
}

\author{
Eduardo Damião da Silva ${ }^{1}$ \\ Rodrigo Souza da Costa ${ }^{2}$
}

\begin{abstract}
Resumo
Este trabalho teve como objetivo discutir epistemologicamente a cientificidade da Administração. Para isso, primeiramente foram colocadas algumas conceituações sobre o método científico para, em seguida, recorrer-se aos critérios de demarcação científica abordados por Karl Popper, Thomas Kuhn e Imre Lakatos, e quais suas decorrências para conceituar-se a Administração como ciência. Pode-se inferir que a Administração apresenta características que permitem classificá-la como uma área científica. Isto é dito depois de se verificar a possibilidade de falseamento de estudos, conforme a ideia do falseacionismo sofisticado de Popper. O mesmo ocorre no que se refere aos postulados sobre os paradigmas de Thomas Kuhn. Também se adéqua, de forma mais visível, aos programas de pesquisa apresentados por Lakatos. Por fim, conclui-se que a Administração possui um objeto de estudo, ainda em processo de formação, o que faz com que a área seja uma ciência nova. A Administração é uma ciência prática, pois está relacionada com a resolução de problemas da realidade, mas não somente se ocupa com a solução de problemas, pois também aumenta seu conhecimento de seu objeto e da realidade.
\end{abstract}

Palavras-chave: Administração. Cientificidade. Epistemologia.

\begin{abstract}
This work aimed to discuss epistemologically the scientificity of administration. In order to do this, some conceptualizations on the scientific method were first proposed, followed by the criteria of scientific demarcation discussed by Karl Popper, Thomas Kuhn and Imre Lakatos, and their consequences for conceptualizing administration as a science. It can be inferred that the administration presents characteristics that allow to classify it as a scientific area. This is said after verifying the possibility of falsifying studies according to the idea of Popper's sophisticated falsificationism. The same holds true for the postulates about the paradigms of Thomas Kuhn. It also fits in a more visible way to the research programs presented by Lakatos. Finally, we conclude that the administration has an object of study, still in the process of formation, which makes the area a new science. The administration is a practical science because it is related to the resolution of problems of reality, but not only deals with the solution of problems but also increases its knowledge of its object and reality.
\end{abstract}

Keywords: Management. Scientific. Epistemology.

\section{Introdução}

Dentro dos estudos na área de Administração, há uma crescente preocupação com a qualidade dos trabalhos que são produzidos. Logo, também emergem questões relativas à coerência epistemológica nas pesquisas da área. Há argumentos que sustentam que algumas áreas seriam ramos da ciência que não possuem métodos e técnicas próprias de pesquisa e se utilizam de procedimentos metodológicos de outras

Prof. Dr. Titular da Pontifícia Universidade Católica do Paraná. PUCPR / PPAD / PPGCOOP. Ph. D. pela ESADE - Escuela Superior de Administración y Dirección de Empresas - Barcelona. Afiliação: Pontifícia Universidade Católica do Paraná. Brasil. Lattes: http://lattes.cnpq. br/8457401494078405 Orcid: http://orcid.org/0000-0002-8182-6394 Email: eduardo.damiao@pucpr.br

2 Doutor em Administração pela Pontifícia Universidade Católica do Paraná (PPAD/PUCPR). Afiliação: Pontifícia Universidade Católica do Paraná. Brasil. Email: mscrodrigodacosta@gmail.com 
áreas (BUNGE, 1980). Desse ponto de vista, a Administração seria uma dessas áreas que não possuem esses métodos e que se utilizam de técnicas de outras ciências, tais como Psicologia, Economia e Antropologia. Além disso, mesmo com esse argumento sendo relativamente muito abordado por aqueles que não consideram a Administração como uma ciência, uma crítica feita, sobretudo, por pesquisadores das chamadas ciências duras, como a Física, a Química etc., é que a área não atende aos critérios de demarcação científica (POPPER, 1968; KUHN, 1975; LAKATOS, 1979) nas pesquisas que são publicadas. Entretanto ressalta-se, aqui, a importância dessa discussão, tendo em vista que a área é relativamente nova em comparação com outras áreas científicas, que possuem um nível maior de maturidade por terem acumulado conhecimentos e preocupações com o rigor científico ao longo de séculos (BUSANELO; SCHLICKMANN, 2010). Logo, à medida que as pesquisas em Administração avançam, surge a necessidade de entendimento de como tem se dado o desenvolvimento do campo de pesquisa.

A análise epistemológica da Administração gera pontos de vista diversos e controversos e, obviamente, ainda não há um consenso acerca da sua cientificidade, pois essa definição depende, também, dos critérios de demarcação do que é ciência ou não ciência, utilizados para analisar o campo da Administração. Entretanto, mesmo as ciências ditas "hard" também não se utilizam apenas de disciplinas de suas respectivas áreas, bem como a Economia (que sempre é utilizada como exemplo de ciência social que atende a critérios de demarcação de cientificidade reconhecidos) e também não se classificaria como ciência que utilize somente métodos próprios. A linha de pensamento de alguns autores (DUFOUR, 1992; BERNARDES; MARCONDES, 2006; MINTZBERG, 2006) é que a Administração não é capaz de gerar conhecimento confiável, pois "o conhecimento nela produzido não se qualifica como sendo algo objetivamente provado" (CHALMERS, 1993, p. 23). Alguns pesquisadores a defendam como uma ciência social aplicada (TAFFAREL; SILVA, 2013; CAMPANARIO; CHAGAS JR.; RUIZ, 2012; WALTER; ROCHA, 2011; LEMOS; BAZZO, 2011;DAMKE; WALTER; SILVA; 2010).

Na descrição histórica de Kuhn (1975) sobre a atividade científica é estabelecida a sua vinculação com a dinâmica de uma comunidade científica. É essa comunidade que estabelece o que é ou não aceitável em termos de se fazer ciência no campo de conhecimento (KUHN, 1975). Portanto, não se pode simplesmente ordenar que a produção científica, num determinado campo do conhecimento, seja feita de acordo com outros interesses que não os da comunidade científica do referido campo. Essa confusão fica em destaque quando se colocam ciência e P\&D (pesquisa e desenvolvimento) como sendo a mesma coisa. Partindo dessas questões, é importante diferenciar, em diversos sentidos, o que seria: 1) ciência básica, 2) ciência aplicada, 3) prática e 4) produção comercial (BUNGE, 1980). A ciência básica tem como propósito o enriquecimento do conhecimento humano acerca de uma determinada área do conhecimento. Já a ciência aplicada emprega os conhecimentos obtidos nas pesquisas básicas, ou seja, ela vai utilizar as mesmas técnicas e métodos da ciência básica para o entendimento de objetos de estudo mais particulares e, além disso, ela vai buscar gerar novos conhecimentos e que sejam mais específicos em relação ao fenômeno estudado. Ainda se tem a prática, a qual não produz conhecimento, mas sim técnicas que serão utilizadas pelos praticantes. Dessa forma, para o praticante, a ciência não é um fim, mas um meio. Por fim, há a produção comercial, que busca gerar instrumentos que beneficiarão a sociedade, por vezes ocasionando equívocos de distinção entre produção industrial e produção científica (BUNGE, 1980).

Tendo em vista as considerações apresentadas até aqui, cabe aos pesquisadores da área, dedicados às questões epistemológicas, buscar argumentos para verificar se e como a Administração se constitui como uma ciência. Dessa forma, o objetivo primordial desse ensaio é desenvolver uma reflexão acerca dos critérios de demarcação científica e, consequentemente, a sua aplicabilidade como um esforço válido para a caracterização científica da área da Administração. Para alcançar esse objetivo, ao longo do trabalho, serão utilizados, num primeiro nível, os critérios epistemológicos e de demarcação científica que foram propostos pelos filósofos da ciência Karl Popper, Thomas Kuhn e Imre Lakatos. Num segundo nível, esses critérios serão complementados e contrastados com outras visões, como de Weber, Schultz, Albach, Figueiras, Burrel e Morgan, Faria, Habermas, entre outros. Para isso, o trabalho foi estruturado da seguinte forma: primeiramente, elabora-se uma revisão teórica da obra dos autores citados, com o intuito de clarificar as suas principais ideias acerca de suas perspectivas epistemológicas. A seguir, levanta-se uma discussão sobre a cientificidade do campo da Administração, tendo como norteamento os critérios de demarcação 
utilizados pelos filósofos da ciência citados. Por fim, descrevem-se as considerações finais do trabalho, bem como algumas perspectivas futuras que merecem atenção.

\section{A natureza científica}

Para iniciar a abordagem do tema, é importante considerar o que sustentam as principais teorias sobre 'natureza científica' (CHALMERS, 1993). Inicialmente, havia uma visão comum de ciência, conforme a qual era considerado científico (e, portanto, 'verdadeiro') o conhecimento provado por base empírica (POPPER, 1975; LABORIT, 1988, CHALMERS, 1993). Essa forma de fazer ciência, chamada de "indutivismo", parte do princípio de que leis e teorias gerais podem derivar de observações de certa quantidade de fatos. Logo, a observação de alguns fatos geram, por indução, a formulação de leis gerais ou teorias. Sendo assim, o indutivismo é um meio de formalizar a visão do senso comum.

O filósofo escocês David Hume destacou o que foi considerado um dos principais problemas filosóficos no campo da Filosofia da ciência, que era o denominado "problema da indução". A essência do problema da indução reside no fato de que, aplicando o pensamento lógico à indução, por maior que seja o número de observações particulares realizadas, não consegue garantir a verdade de uma teoria ou proposição geral. Dessa forma, partindo justamente de uma abordagem lógica, o "falsificacionismo" de Popper (1968, 1975) surge como uma alternativa ao indutivismo, pois rompe com a lógica indutiva e apresenta a lógica hipotético-dedutiva, que destaca que, pela indução, também não se pode provar a verdade de uma teoria, mas que se pode provar que ela é falsa. Com a explicação falsificacionista, a construção da ciência passa não a buscar "verdades absolutas", mas, sim, colocar essas teorias, de forma empírica, à prova, visando falseá-las. Com isso, Popper coloca que uma proposição só pode ser considerada científica se ela for falsificável, do ponto de vista hipotético-dedutivo, ou seja, se a proposição ou teoria puder ser submetida à crítica, entendendo crítica como a possibilidade de testar a teoria, ou seja, a possibilidade de falseá-la. A partir do momento em que uma proposição for falseada (não confirmada), poderá ser substituída por uma nova, desde que essa nova teoria explique o que a teoria anterior (falseada) explicava e consiga superar o teste que a predecessora não conseguiu superar, ou seja, consiga explicar o que a teoria falseada não conseguiu explicar. Essa estrutura lógica permite que ocorra um progresso científico, algo não considerado no indutivismo (POPPER, 1968; 1975). Nessa visão, o progresso científico se dá por substituição de teorias, e não por acumulação, como pressupunha o indutivismo.

Entretanto, mesmo sendo, para Popper, um modo mais consistente, o falsificacionismo sofre com críticas, sobretudo por uma inadequação histórica. Além disso, o trabalho científico não pode se resumir a tentativa de falseamentos de teoria (KUHN, 1975). Partindo das dificuldades enfrentadas pela visão popperiana emerge a visão de que teorias científicas devem ser vistas como estruturas ao invés de teorias isoladas (KUHN, 1975). Dessa forma, emerge a noção de "paradigma" kuhniano, que seria um modelo genérico que orienta as explicações científicas sobre o mundo e direciona a chamada "ciência normal" uma espécie de tradição científica. A ciência normal, de tempos em tempos, enfrenta o desafio de ter que resolver anomalias no paradigma, o que normalmente consegue. No entanto, quando as anomalias não são superadas e aumentam de maneira persistente, dão origem a uma crise do paradigma vigente, o que é chamado por Kuhn de "ciência extraordinária", que é quando a crítica ao paradigma vigente ocorre.

Quando surge um novo paradigma que dá conta de resolver tudo que o paradigma até então vigente resolvia e também resolve as anomalias que esse paradigma não resolveu, ocorre a quebra de paradigma ou a "revolução científica". O entendimento do termo paradigma se apresenta como uma das principais dificuldades iniciais do pensamento de Kuhn (1975). Pensadores, filósofos e pesquisadores, em muitas áreas, se apropriaram do termo de acordo com os seus interesses, ampliando a já confusa compreensão do significado de paradigma. Isto ocorreu, também, na área da Administração. Discutiremos isso mais adiante, quando será abordada a contribuição de Burrel e Morgan sobre paradigmas no campo da Administração. Uma segunda visão do trabalho científico como estrutura é apresentado por Imre Lakatos (1979), que segue uma linha popperiana e, consequentemente, elabora postulações que vão ao encontro do pensamento original de Popper (1968). Em suma, a visão lakatosiana consiste em uma metodologia de programas de pesquisa, em que há um núcleo irrefutável que contém os princípios essenciais de uma determinada 
teoria. Esse núcleo é protegido pelo que o autor chama de "cinturão de hipóteses auxiliares", ou teorias auxiliares e estas, sim, podem ser alteradas de acordo com a criatividade dos cientistas para resolverem as anomalias que, por ventura, surjam, ou reforçar o cinturão e aumentar a proteção do núcleo irrefutável (LAKATOS, 1979). Nas subseções seguintes, serão aprofundados os pontos de vista que foram introduzidos até aqui acerca do trabalho científico segundo a ótica do falsificacionismo de Popper, dos paradigmas de Kuhn e dos programas de pesquisa de Lakatos, buscando descrever como a área de Administração se apropriou de cada uma dessas óticas e como elas podem ser aplicadas para aprofundar a reflexão acerca da cientificidade da Administração.

A escolha das abordagens filosóficas de Popper (1968), Kuhn (1975) e Lakatos (1979) como os critérios a serem considerados num primeiro nível, neste trabalho, reside no fato de que essas três abordagens são, reconhecidamente, as principais referências do ramo da Filosofia da ciência do século XX. Elas representam as contribuições filosóficas que mais tiveram implicações na discussão do segundo maior problema da Filosofia da ciência, que é o problema da demarcação (POPPER, 1975). Além disso, essas três visões representam estruturas lógicas que podem ser traduzidas para qualquer área do conhecimento, ou seja, tanto para Ciências Naturais quanto para as Ciências Sociais.

\subsection{O falsificacionismo de Karl Popper}

Popper (1968) denominou seu pensamento filosófico utilizando o termo "racionalismo crítico" como uma forma de mostrar seu descontentamento com o empirismo clássico, que representava o indutivismo. Em relação às abordagens sobre o conhecimento, Popper (1968) aborda que esse conhecimento é objetivo e que seria a ampliação do conhecimento mediante repetitiva resolução de problemas e crítica às teorias, a partir de testes possibilitados pela existência de uma base empírica, mas numa lógica hipotético-dedutiva. Ao longo do percurso de desenvolvimento científico, os pesquisadores são passíveis de falhas, do mod que equívocos podem ser cometidos durante o caminho da investigação científica. Dessa forma, ele elabora uma crítica ao método indutivo (predominante até então), pois esse método geraria inferências generalizadas que podem ser errôneas, tendo em vista que se parte de dados de observações, e que, mesmo pressupondose uma imparcialidade por parte do observador, é inviável que observe uma quantidade suficiente de acontecimentos que possa ser considerada como uma 'verdade universal'.

O método hipotético-dedutivo proposto pelo falsificacionismo como forma de gerar conhecimento científico passa, primeiramente, pela identificação de um problema, pois, para Popper (1968), a ciência começa pelo problema de pesquisa, que é uma relação entre o conhecido (enunciados, conceitos, variáveis etc.) e o desconhecido (relação entre variáveis, validade dos enunciados etc.). Esse quesito é preenchido pela área, uma vez que as pesquisas realizadas, sobretudo no stricto sensu, partem de problemáticas existentes para dar início às pesquisas. A segunda questão é a formulação de hipóteses, e aqui se tem, também, pesquisas de cunho quantitativo, em que hipóteses são formuladas e testadas por um método dedutivo, que leva à corroboração ou rejeição dessas hipóteses. Em havendo a rejeição, uma nova teoria poderá emergir, ou a teoria refutada poderá ser reformulada para ser testada novamente (POPPER, 1968; 1975).

Outra questão abordada por Popper (1968) remete à inexistência de neutralidade no processo de observação no método indutivo, pois o pesquisador nunca consegue se livrar integralmente de pressupostos, ou mesmo de elementos da sua personalidade. Desse modo, a verdade universal pregada pelo método indutivo pode, quando muito, ser considerada válida até ser testada e provada como falsa. Entretanto mesmo com os eventuais equívocos que o pesquisador possa cometer, ainda assim esses erros seriam fonte de aprendizagem para geração de teorias menos falíveis e que poderão ser testadas futuramente. Dessa forma, não se pode justificar as teorias, mas pode-se utilizar do racionalismo para criticá-las e adotar (mesmo que de forma provisória) as teorias que melhor expliquem os pontos criticados, sempre levando em consideração que as próprias teorias estão sujeitas a reformulações.

Popper também faz uma crítica ao filósofo inglês Francis Bacon - que foi um defensor do método indutivo -, pois ele afirmava que era necessário limpar a mente de ídolos e de teorias para se alcançar o saber verdadeiro. Para Popper (1968), Bacon buscou resultados na mente vazia, e o progresso só acontece com a crítica. De acordo com Popper, para que uma nova teoria se constitua em um avanço, deve haver um 
conflito com a teoria vigente, fazendo com que o papel da crítica seja essencial para o avanço científico. 0 autor vai além e explana que, para superar a anterior, a nova teoria deve apresentar resultados superiores, devido ao fato que a ciência está sempre em progressão, pois ela é revolucionária. Nesse ponto em particular, é possível verificar certa crítica ao ponto de vista defendido por Kuhn (1975), em sua obra, como será esclarecido na próxima sessão.

Para Popper (1968), a ciência se baseia no processo de observação e construção teórica, sendo assim, só se pode concluir sobre fenômenos observados, nunca sobre o que não foi. Mesmo assim, qualquer tipo de hipótese formulada de maneira científica, baseada em observação, jamais deve ser acatada como uma verdade absoluta e, dessa maneira, qualquer teoria científica poderá ser considerada válida até que se apresente o falseamento por outra teoria que tenha um poder maior de explicação - ou seja, que por meio de testes se mostre mais abrangente. A possibilidade de refutação de uma teoria que constituiria, para Popper (1968), a essência da natureza científica: qualquer teoria só será considerada científica (sob a ótica popperiana) quando houver a possibilidade de falseá-la, ou seja, quando a teoria puder ser criticada. Dessa forma, justifica-se a afirmação de Popper de que toda teoria é uma conjectura. Em suma, se não se pode falsear ou refutar determinada teoria, não é possível considerá-la científica.

\subsection{Os paradigmas de Thomas Kuhn}

Ao abordar a natureza da ciência, Thomas Kuhn (1975) discorre sobre uma ciência paradigmática. Para isso, o autor dá ênfase à necessidade de estudos de maior profundidade acerca da estrutura comunitária da ciência e de outras áreas de estudo, sobretudo estudos de ordem comparativa. De forma mais específica, o autor destaca aspectos que, no conjunto, distinguem o trabalho científico pertinente às Ciências Naturais, notadamente: (i) julgamento pelos próprios membros do grupo; (ii) educação científica por meio de manuais; (iii) existência de quebra-cabeças possíveis e modelos; (iv) sistema de valores razoavelmente rígidos; (v) desenvolvimento da ciência normal ligado à tradição, com períodos de ruptura. Este último aspecto é, isoladamente, segundo Kuhn (1975), partilhado por outras áreas do conhecimento, tanto das Ciências Naturais como outras ciências, como História da Literatura, Música, Artes, o Desenvolvimento Político, entre outras. Além disso, o autor explica que uma importante crítica dos popperianos em relação à ciência normal é que o cientista deve sempre ser um crítico e buscar gerar teorias alternativas.

Kuhn (1975), entretanto, não rejeita essa possibilidade, mas destaca que o rompimento do período de ciência normal deve ser feito de forma parcimoniosa, de modo que se explorem os referenciais antes de descartá-los, o que ocorre em raros momentos, quando a crise se instala e dá início ao período de ciência extraordinária. Da mesma forma, a crítica de Popper (1975) à ciência normal kuhniana está na falta de elementos críticos que, segundo ele, são atividades de profissionais não revolucionários. Popper não nega que o período de ciência normal exista, apenas sustenta que esse processo é demasiadamente lento, o que poderia gerar uma doutrinação, sobretudo na forma como os historiadores da ciência ensinam em nível superior. Segundo Popper (1975), os historiadores da ciência não utilizam o elemento crítico em suas análises, e vão simplesmente solucionar enigmas dentro da ciência normal. É o que o autor chama de "perigo da ciência normal". Popper (1975) critica a atitude de achar normal o período de ciência normal, justamente pelo fato do cientista não apresentar a atitude de crítica e se contentar em resolver enigmas. Atitude crítica que somente ocorrerá no momento de ciência extraordinária. Entretanto Kuhn (1975) deixa implícito que, na ausência de um paradigma (ou de alguma teoria que seja candidata), todos os fatos que, possivelmente, são pertinentes ao desenvolvimento de determinada ciência têm probabilidade de parecerem igualmente relevantes.

Inicialmente, Kuhn (1975, p. 13) define "paradigmas" como sendo "as realizações cientificas universalmente reconhecidas que, durante algum tempo, fornece problemas e soluções modelares para uma comunidade de praticantes de uma ciência". Porém, de acordo com o autor, grande parte dos cientistas passam considerável parte das suas carreiras preocupados com a limpeza do paradigma estabelecido. Essa operação é o que o Kuhn (1975) define como período de "ciência normal", sendo que essa ciência normal não busca trazer novos fenômenos, pois a pesquisa está direcionada para a articulação dos fenômenos e teorias previamente fornecidos pelo paradigma vigente. Mas mesmo essa ciência dita 'normal' possui um 
mecanismo de inovação intrínseco, que é o aperfeiçoamento das teorias para continuarem resolvendo os problemas da área e darem conta das anomalias surgidas. Nesse período, o avanço do conhecimento dá-se por acumulação. Mas, segundo Kuhn (1975), a "revolução científica" (que em função do relaxamento dos fatores que limitam a pesquisa e, dessa forma, o paradigma do qual esses fatores derivam deixa de funcionar efetivamente) ocorrerá somente quando surgir um novo paradigma que resolva todos os problemas que o paradigma vigente resolvia e dê conta de resolver os problemas novos, não resolvidos pelo paradigma vigente até então.

É necessário que as crises, que estão relacionadas ao surgimento de novas teorias, aconteçam para que emerjam novas teorias, pois, para Kuhn (1975, p. 23), essas "crises são uma pré-condição necessária para o surgimento de novas teorias". Em outras palavras, para que se estabeleça um paradigma, faz-se necessário que se tenha novas teorias que possam resolver as anomalias que surgiram. Nesse período de crise, quando os cientistas percebem que há algo essencialmente errado no paradigma, dá-se início ao período denominado por Kuhn (1975) de "ciência extraordinária", que se diferencia da pesquisa em períodos de ciência normal por apresentar um caráter mais hipotético e incompleto do que fora afirmado anteriormente por filósofos da ciência, e mesmo por outros cientistas. Aqui, faz-se necessária uma análise filosófica de regras e de pressupostos mais consistentes durante essa revisão, pois a verificação de paradigmas escolhe a alternativa mais viável dentre as existentes no contexto em que se encontra. Finalizando a visão kuhniana, o próprio autor admite que, em seus primeiros escritos, a definição de paradigma não fica clara, tendo ele definido o termo de forma diferente por mais de vinte vezes ao longo da obra, de modo que, em sua definição mais aprofundada, o termo paradigma significa:

[...] oferecer problemas-exemplo, ou quebra-cabeças, compartilhados pela comunidade de pesquisadores que está associada ao paradigma. [...] os cientistas resolvem quebracabeças modelados de acordo com soluções anteriores, frequentemente com um recurso mínimo a generalizações simbólicas (KUHN, 1975, p. 235).

Assim, no que se refere à figura do pesquisador perito na solução dessesquebracabeças, de acordo com Kuhn (1975), a ciência normal oferece problemas com solução possível, que evitem problemas muito complexos ou metafísicos. Para ele, uma das razões pelas quais a ciência normal parece progredir de forma rápida é que seus praticantes tendem a empregar esforços em problemas que somente a sua falta de engenho pode impedir de resolver. Vale ressaltar que o teste de paradigma acontece somente após o fracasso persistente na resolução de um determinado quebra-cabeça importante dar origem a uma crise. No entanto nenhuma teoria resolverá todos os quebra-cabeças com os quais se defronta em um dado momento, assim as soluções encontradas nem sempre são perfeitas.

\subsection{Os programas de pesquisa de Imre Lakatos}

Lakatos (1979) busca seguir os ensinamentos popperianos e, de certa forma, expandi-los, expondo a metodologia dos programas de pesquisa científica como uma explicação lógica do que seria fazer ciência. Para esse filósofo, os relatos indutivistas e falsificacionistas da ciência apresentam falhas por não levarem em consideração o quão complexo seria o estudo histórico das principais teorias científicas. Sendo assim, ele procurou verificar como a razão e a história constroem o processo de crescimento e desenvolvimento do conhecimento científico. O autor analisa o que ele chama de "falseacionismo dogmático", que é desenvolvido por conjecturas ousadas e falsificações infalíveis, observando que tal postura está equivocada, pois a base empírica da ciência é formada por proposições de observações que estariam sujeitas a erros por parte do pesquisador.

Em contrapartida, também se verifica a existência do "falseacionismo metodológico ingênuo", que vem a corrigir o que é proposto pelo falseacionismo dogmático. Contudo também não se apresenta de forma satisfatória para Lakatos (1979), pois pressupõe que a ciência se desenvolva por uma série de disputas sucessivas entre a teoria e os fatos. Devido ao exposto, Lakatos (1979) coloca que a discussão entre o teórico e o factual acontece entre duas teorias em competição e os fatos reais. Sendo assim, de acordo com o autor, não se pode descartar uma teoria tão somente quando algum fato a contradiz. A eliminação da 
teoria aconteceria apenas quando surge uma teoria melhor que a anterior, ou seja, uma teoria que explique o que a anterior (descartada) explicava, e consiga ir além, agregando conhecimento à comunidade científica. Dessa maneira, uma teoria só será aceita como científica se proporcionar conteúdo empírico corroborado em excesso quando comparado com a teoria predecessora ou rival (LAKATOS, 1979, p. 141).

O que Lakatos (1979) coloca é que a ciência é feita pela competição entre programas de pesquisa rivais que, segundo o mesmo, seria a ideia central do chamado "falseacionismo metodológico sofisticado". A ideia central da obra de Lakatos (1979) consiste na noção de um "programa de pesquisa", que seria uma estrutura formada por um núcleo irredutível de hipóteses básicas das teorias levantadas, que seria protegido por um cinturão de hipóteses auxiliares, e também pelo que o autor chamou de heurísticas positivas e negativas. São as heurísticas que coordenam o processo de investigação científica. De acordo com o autor, a 'heurística positiva' consiste num conjunto articulado de sugestões ou palpites sobre como mudar e desenvolver as "variantes refutáveis" do programa de pesquisa e sobre como modificar e sofisticar o cinto de proteção "refutável". Já a 'heurística negativa' são as hipóteses auxiliares, formuladas para resolver as anomalias, e as condições iniciais formam o "cinto de proteção" do programa (LAKATOS, 1979, p. 164). Além disso, o autor busca mostrar que a não refutação imediata das teorias permite o progresso da ciência. Essa visão fica clara quando o autor apresenta sua concepção com relação ao papel da crítica na construção do conhecimento:

A crítica destrutiva como a "refutação" ou a demonstração de uma inconsistência não elimina um programa. A crítica de um programa é um processo longo e amiúde frustrante, e os programas em desenvolvimento devem ser tratados sem severidade (LAKATOS, 1979, p. 222).

Como forma de avaliar os programas de pesquisa, Lakatos (1979) ilustra seu argumento com base nos programas de Prout e Bohr, tendo-se critérios que permitem classificá-los em progressivo e degenerativo. Nesse sentido, um programa de pesquisa é progressivo quando as modificações no cinturão protetor possibilitam a previsão de novos fatos. Em contrapartida, um programa é degenerativo quando os ajustes não apresentam a possibilidade de prever fatos novos ou, ainda que ocorra uma previsão, não é possível corroborá-la. Segundo Lakatos (1979), as revoluções científicas apenas ocorrem se houver dois programas de pesquisa rivais e que um deles progrida enquanto o outro degenere, fazendo com que os pesquisadores passem a estudar a partir do programa progressivo. Porém essa superação de programas concorrentes não é um processo imediato. A substituição do programa de Bohr pelo de Prout, ilustrado no exemplo, ter ocorrido enquanto o programa de Bohr estava degenerando foi apenas mera coincidência. Após isso, Lakatos (1979, p. 246) volta a tecer críticas à ciência normal de Kuhn quando coloca que "a história da ciência tem sido de programas de pesquisa competitivos (ou de "paradigmas"), mas não deve ser, uma sucessão de períodos de ciência normal". Para o autor, a visão kuhniana considera que a revolução científica é irracional, uma questão de psicologia das multidões, que mais tarde é chamada de "psicologia social". Para Popper (1975) e Lakatos (1979), a descrição de que a mudança de paradigma se dá como um processo de conversão, e que os pesquisadores passam a ser adeptos de uma novo paradigma, introduz uma irracionalidade para o campo da ciência que deve ser evitada, pois o caminho da ciência é o da construção do conhecimento objetivo, que somente é possível por meio do processo racional.

\section{A Administração é uma ciência? Reflexão acerca da sua cientificidade}

Este é um questionamento controverso, tendo em vista a quantidade de autores que já buscaram respostas (BURREL e MORGAN, 1979; MORGAN, 1980; DAMKE; WALTER; SILVA, 2010; MATTOS, 2003; 2009; SERVA, 2013) e expressaram opiniões divergentes no que tange a definição do campo da Administração. Nesse sentido, temos os que classificam a Administração como uma ciência e também temos os que defendem que a Administração não é uma ciência. De certo ponto de vista, pode-se considerá-la como ciência devido ao fato de possuir um corpo teórico próprio que possibilita indicar formas de comportamento em casos específicos, tendo resultados previsíveis (MATTOS, 2009). Esse corpo teórico foi desenvolvido por parte de uma comunidade de pesquisadores que, no seu fazer pesquisa, adotaram uma postura de rigor científico, 
se alinhando-se a um dos ou a todos os critérios de demarcação de ciência descritos por Popper (1968), Kuhn (1975) e Lakatos (1979), que serão destacados separadamente a seguir. Quem compartilha dessa opinião está construindo a sua análise a partir de um ponto de vista que direciona o foco para a comunidade de pesquisadores que gera o conhecimento em Administração, a partir de um rigor metodológico. Por outro lado, existem os que não consideram a área uma ciência, por depender que sejam desenvolvidas habilidades intuitivas, em que os riscos desse comportamento não podem ser previstos, sendo uma competência para atingimento de um resultado (AKTOUF, 1996; MATTOS, 2009). Essa opinião é compartilhada por aqueles que possuem outro olhar, que direciona o foco para o praticante (o gestor) que, no seu dia a dia, assume riscos e necessita ser criativo e inovador para atingir os resultados traçados. Esse gestor nem sempre insere no processo decisório a racionalidade ou o rigor que caracteriza o processo científico.

Também se podem questionar outros pontos que ainda colocam em dúvida a cientificidade da Administração, como a proximidade com a prática e a tendência à especialização (ALBACH, 1993), porém essas questões não são suficientes para dar suporte à crítica acerca do caráter científico de uma área de estudo, uma vez que "a prática e a especialização também são elementos inerentes às outras ciências, pois jamais um indivíduo poderá ter a certeza de alcançar qualquer coisa verdadeiramente valiosa no domínio da ciência, sem possuir uma rigorosa especialização" (WEBER, 2007, p. 24). É necessário, portanto, que sejam relacionados e aplicados os critérios de demarcação do que é ciência e não ciência, descritos nos itens anteriores a partir da visão de Popper (1968), Kuhn (1975) e Lakatos (1979), que são os representantes da filosofia da ciência que mais avançaram na discussão sobre o problema da demarcação de ciência e na definição de critérios que permitem a avaliação das áreas de conhecimento, mas contrastados com os tipos de conhecimentos gerados no campo da Administração. Por isso, a utilização das contribuições de Albach, Weber, Morgan, Mattos, Damke, Walter e Silva, Bunge, que são autores reconhecidos da Administração, ou vinculados à área, desenvolvendo as suas críticas, análises e contribuições a partir do arcabouço teórico de Administração. A partir desse ponto, apresentaremos algumas visões de autores que trabalham critérios para a demarcação da ciência no campo das Ciências Sociais.

Figueiras (1973), em "Metodologia das Ciências Sociais", fala sobre a aplicação da lógica na elaboração de teorias. Figueiras (1973) afirma que a relação entre teorias e realidade é o objeto do critério de validade. "A validade nos ajuda a ter uma garantia da teoria que aplicamos. Chegamos a conhecer a validade de uma teoria pelo processo de verificabilidade. Como na prática é impossível verificar de um modo positivo que uma afirmação é válida em todos os casos existentes e possíveis, recorremos ao método da falsificação" de Popper.

Visando discutir e aprofundar o caráter científico da Administração, Albach (1993) coloca quais seriam os critérios para podermos enquadrar os estudos em Administração como científicos, por que ele trabalhou em critérios de demarcação da ciência. Albach (1993) lida especificamente com a Administração como uma ciência, que é classificada como uma Ciência Social Prática ou Aplicada à Ciência Social. Albach (1993) apresenta a visão de alguns autores que definem certos critérios para avaliar a Administração como ciência. De acordo com Albach (1993), para Gutenberg, o critério para que pudesse ser considerado como uma ciência era que as declarações "se-então" pudessem ser formuladas.

Albach (1993) cita que Max Weber exigiu que as ciências fossem "livres de juízos de valor". No entanto, livre de juízos de valor não exclui uma orientação para objetivos econômicos e sociais concretos e que são diferentes de empresa para empresa. Outro critério indicado é a validade das afirmações no espaço e no tempo. Para facilitar isso, é necessário especificar bem o objeto da investigação. O quarto critério citado por Albach (1993) é a objetividade das declarações científicas. Segundo ele, são objetivos quando podem ser verificados por terceiros e aplicados. "As declarações empíricas devem ser tais que possam ser repetidas". Finalmente, como um quinto critério, o autor apresenta a condição de falseabilidade de Popper. No entanto, Albach (1993) diz que alguns cientistas não consideram a busca de exemplos contraditórios, como exige Popper, mas que, seguindo Kuhn, como estudantes muito zelosos, consideravam a busca por seguidores crentes de seu novo "paradigma".

Albach (1993) resume dizendo que "as afirmações 'se-então' (causalidade), a 'liberdade de juízos de valor', a validade das afirmações no espaço e no tempo, objetividade e falseabilidade, são os cinco critérios que eles são exigidos de um sistema de enunciados para ser considerado como uma ciência". 
Para Albach (1993), a Administração é uma ciência orientada para a solução de problemas. Outra análise que faz é sobre a evolução de alguns paradigmas que impulsionam a Administração na Alemanha. O autor cita o paradigma de Gutenberg, fundamentalmente orientado para a produtividade, nos anos 50 .

Esses critérios de demarcação da ciência, tanto os procedimentos metodológicos de Popper, Kuhn e Lakatos quanto os procedimentos apresentados para as Ciências Sociais, especialmente para a Administração, por autores como Albach, Gutenberg e Figueiras, serão utilizados como referência para a análise sobre a cientificidade da Administração de empresas.

\section{Critérios de demarcação da Administração como ciência}

Ao se analisar os critérios de demarcação fica a impressão de que, muitas vezes, Popper (1968; 1975) e Kuhn (1975) estão discorrendo sobre os mesmos pontos utilizando terminologias distintas, pois o que é ciência normal na perspectiva kuhniana, se parece com as tentativas de falseamento das hipóteses popperianas. Essas hipóteses (ainda não falseadas) poderiam ser comparadas aos paradigmas de Kuhn (1975). E ainda temos Lakatos (1979), que busca a construção de programas de pesquisa como uma espécie de evolução dos ensinamentos do racionalismo crítico de Popper (1968). Sendo assim, o que poderia se utilizar para determinar a cientificidade do campo da Administração seriam os critérios de demarcação que foram definidos pelos autores. De um lado, Popper (1968; 1975) coloca que uma área para ser considerada científica deveria ter suas pesquisas direcionadas à possibilidade de falseamento de hipóteses, utilizandose de métodos objetivos para isso, ou seja, a área deve permitir a crítica, que é o que lhe dá status de cientificidade na visão popperiana. Kuhn (1975), por outro lado, ressalta que o estabelecimento de paradigmas é fator essencial para uma área científica, desde que acompanhado do processo de ciência normal, ciência extraordinária, crise do paradigma e revolução (quebra e substituição do paradigma). Por fim, Lakatos (1979) coloca que qualquer área científica deve ser formada pelos programas de pesquisa (progressivos vs. degenerativos). Tendo em vista o exposto, nas seções a seguir parte-se para uma análise da área de Administração sob a luz dos critérios de demarcação estabelecidos pelos filósofos citados.

\subsection{A administração a partir do Falsificacionismo Popperiano}

Popper rejeita a lógica indutiva, como fizeram os membros do Círculo de Viena, no qual a concepção positivista foi baseada. No entendimento de Popper, apenas a lógica dedutiva permite uma avaliação segura da validade das proposições científicas. Para chegar a essa conclusão, Popper realiza um trabalho de reconstrução lógica que o leva a questionar também o critério de demarcação proposto pelo Círculo de Viena.

Para Popper, o critério de demarcação é um dos elementos centrais com os quais a epistemologia deve lidar, uma vez que somente com tais critérios seria possível distinguir teorias científicas de teorias não científicas (Popper, 1997). Para os participantes do Círculo de Viena, o critério de demarcação foi a verificabilidade e, posteriormente, a confirmabilidade. Dessa forma, apenas teorias que pudessem ser verificadas ou experimentalmente confirmadas poderiam ser consideradas científicas. Popper rejeita tal proposta, passando a defender a falseabilidade como o único critério possível de demarcação entre ciência e não ciência (Popper, 1997). Segundo Popper, uma teoria poderia ser considerada científica se, e somente se, pudesse ser falseada pela experiência. Dessa forma, "o critério que define o 'status' científico de uma teoria é sua capacidade de ser refutada ou testada” (Popper, 1994, p.66). Esse critério de Popper (falsificacionismo) evolui para o falsificacionismo metodológico (Lakatos et al., 1979). Para o falsificacionismo metodológico, uma teoria só pode ser considerada científica se satisfizer duas condições. Em primeiro lugar, deve poder ser contrastado com uma declaração básica. Segundo, ela deve ser capaz de prever novos fatos, não explicados à luz de teorias anteriores. Essa visão de Popper é conhecida como racionalismo crítico.

As pesquisas realizadas em áreas mais objetivas, como as Finanças, a Gestão de operações e algumas abordagens de Marketing, utilizam-se desse esquema proposto por Popper (1968; 1975). Entretanto sabe-se também que há teorias dentro da Administração que não são passíveis de falseamento por utilizarem uma abordagem de cunho mais subjetivo. Exemplos desse tipo de teorias são as que utilizam uma abordagem marxista ou da psicanálise. 
Köhler (1990) trabalha em seu artigo "Research Methods in Business Administration" o uso lógico de métodos empíricos, além de apresentar a aplicação de testes de hipóteses. Em um contexto de justificação, Köhler (1990) fala de hipótese de tipo lógico e prático. O tipo lógico analisa a parte lógica da definição das hipóteses e verifica se as propostas não são inequívocas. O tipo prático procura contrastar com a prática.

Para Köhler (1990), vários tipos de metodologias podem ser usadas pela Administração, sendo importante, para entender os objetivos, não apenas verificar a hipótese, mas também verificar a relação entre essas hipóteses e fazer a conexão com os objetivos propostos. Essas afirmações de Köhler (1990) indicam a possibilidade da falseabilidade de Popper ser usada como um método para aumentar o conhecimento no campo da Administração. É uma área que tem uma base empírica falseável.

Finalizando, ao considerar grande parte das teorias da Administração, pode-se inferir que elas atenderiam a esse critério específico de Popper (1968), porém a principal característica do critério popperiano é a objetividade do conhecimento.

\subsection{Paradigmas Kuhnianos da administração}

O critério de demarcação de Kuhn (1975) é de que existem paradigmas dominantes em um determinado campo científico e, dentro desse paradigma, os pesquisadores trabalham em período de ciência normal, no sentido de dar consistência àquele paradigma dominante. Porém, de tempos em tempos, haveria a ciência revolucionária, que faria com que houvesse uma transição entre paradigmas (KUHN, 1975). Diversas correntes de pensamento defendem que na Administração ainda estamos caminhando para, em um primeiro momento, dentro de um período pré-paradigmático, buscar algum paradigma. Contudo, ao se analisar o que as teorias da Administração trazem de conhecimento, percebe-se que seus propósitos tendem a ser relativos a um fator comum, almejado pela maioria delas, e que, de alguma forma, poderia ser colocado como um problema natural da Administração: a relação entre eficiência e eficácia na gestão.

Os estudos de Albach (1993) também consideram na Administração, na Alemanha, a presença do paradigma de Gutenberg, orientado para a produtividade, que é seguido por outros paradigmas. Albach (1993), em outro artigo, "Business Administration: History in German-Speaking Countries", também faz uma análise histórica da Administração na Alemanha, identificando novamente o sistema de Gutenberg. Inicialmente, comparando-o com outros desenvolvimentos recentes, dá uma ideia de "evolução" dos paradigmas da Administração na Alemanha. Um estudo semelhante é apresentado por Wöhe (1990), em que também começa com a apresentação do sistema de Gutenberg e, em seguida, apresenta outras abordagens teóricas recentes.

Jensen (1999) e Levie (1995) também realizam análises históricas da Administração de empresas e identificam a existência de paradigmas. Embora esses autores considerem que há alguma confusão, demonstrando uma posição contrária à cientificidade da área, seus estudos comprovam que a história da Administração de empresas indica a existência de paradigmas que buscam a solução dos problemas que surgem nessa área do conhecimento.

Quando Kuhn (1975) afirma que a maturidade vem naturalmente para uma ciência e que as ciências atualmente estabelecidas surgiram de uma área anteriormente mais especulativa, da filosofia natural, da medicina ou do comércio em um período do passado, ele está considerando que outros campos de estudo experimentarão, certamente, a mesma transição no futuro. A Administração, historicamente analisada, mostra sua origem na atividade profissional, mas devido ao aumento dos problemas das organizações, iniciou o processo de transição descrito por Kuhn (1975), rumo a uma situação de maturidade, como as demais ciências já estabelecidas. É por isso que podemos dizer que a Administração é uma nova ciência, em construção, como Kuhn (1975) comenta, que está indo em direção a um processo de desenvolvimento e reconhecimento.

Outro autor que apresenta uma posição a favor da Administração é Gareth Morgan. Morgan (1980) também considera a existência de diferentes paradigmas que buscam explicar a organização. Em seu artigo «Paradigmas, Metáforas e resolver quebra-cabeças», Morgan (1980) argumenta que a teoria social, em geral, e a teoria da organização, em particular, podem ser analisadas com base em quatro maneiras 
diferentes de observar a realidade (paradigmas), as quais refletem diferentes suposições metateóricas sobre a natureza da ciência (dimensão objetiva ou subjetiva) e sobre a natureza da sociedade (dimensão da regulação ou mudança radical).

Morgan também faz uma distinção entre metáfora e pesquisa científica. Para Morgan (1980), a metáfora caracteriza como os seres humanos tentam interpretar o mundo externo por meio de processos subjetivos e do uso de ferramentas (nomes, conceitos, ideias etc.). A pesquisa científica é considerada, por Morgan (1980), como o processo pelo qual o cientista observa o mundo usando metáforas. As metáforas de Morgan (1980) têm importantes implicações no processo de construção de teorias. As metáforas estão mais relacionadas ao processo de descoberta. Segundo Morgan (1980), a ciência da Administração, ortodoxa, baseia-se nas metáforas da organização como uma máquina ou como um organismo.

A partir das ideais de Kuhn (1975), Albach (1993), Jensen (1999), Levie (1995) e Morgan (1980), podemos encontrar diversos estudos históricos sque identificam a existência de paradigmas, segundo a concepção de Kuhn, demostrando um processo evolutivo no conhecimento do campo da administração.

Podemos considerar que a existência de paradigmas orientados ao aumento do conhecimento de uma determinada área de estudo, num processo evolutivo de conhecimento, indica que estamos diante de um processo científico. Dessa forma, as contribuições de Albach (1993), Jensen (1999), Levie (1995) e Morgan (1980) podem nos levar à conclusão de que, pelos critérios de Kuhn (1975), a Administração está num processo de construção da sua cientificidade.

Para concluir, utilizando os critérios de demarcação de Kuhn (1975), encontram-se trabalhos que inferem que a Administração se encontra em um período pré-paradigmático (TAFFAREL; SILVA, 2013; DAMKE; WALTER; SILVA; 2010). Dessa forma, podemos nos arriscar classificando a Administração como uma ciência, pois, de acordo com o critério kuhniano, a transição para a fase pós-paradigmática se dá apenas com a aquisição de um tipo de paradigma, que identifica os quebra-cabeças desafiadores da área do conhecimento, proporcionando pistas para sua solução e garantindo o sucesso do praticante inteligente (KUHN, 1975). A partir da observação com as lentes de Kuhn, a Administração caminha nessa direção.

\subsection{Os programas de pesquisa de lakatos na administração}

Conforme já explanado, a ideia de Lakatos (1979) consiste na noção de um programa de pesquisa que seria uma estrutura composta de um núcleo irredutível de hipóteses básicas das teorias levantadas, que seria protegido por um cinturão de hipóteses auxiliares e também pelas heurísticas positivas e negativas.

A partir do critério de demarcação de Lakatos, em que "um campo de estudo é uma ciência se se ajusta à metodologia dos programas de pesquisa científica e não é se não se ajusta" (Chalmers, 1997, p. 151), podemos citar a teoria da decisão de Gutenberg, a teoria dos sistemas (sistema socioeconômico) e a escola do comportamento humano como exemplos de abordagens que se equivalem com a ideia de programas de investigação científica de Lakatos. As escolas de Administração, atualmente, desenvolvem programas de pesquisa de diversas áreas da Administração, publicando artigos que refletem a evolução desses programas. Podemos citar como exemplo a área dos "sistemas de informações" e, dentro desta, o programa de pesquisa sobre "gestão do conhecimento". Esses exemplos ilustram a aplicabilidade das ideais de Lakatos na área da Administração, o que comprova, segundo o critério de demarcação do autor, a cientificidade dessa área do conhecimento.

Entretanto essa divisão muito ampla entre as áreas que formam a ciência como um todo pode ser explicada - utilizando-se da noção de programas de pesquisa de Lakatos - da seguinte forma: cada uma dessas (sub)áreas, com suas teorias correspondentes, compõe um programa de pesquisa com seus próprios núcleos e hipóteses (LAKATOS, 1979). Sendo assim, uma das críticas feitas à Administração com relação à fragmentação interna de áreas que a compõem, seria sanada. Partindo dessa premissa, dentro da Administração há algumas áreas que podem ser consideradas programas de pesquisa, a exemplo da área de Estudos Organizacionais, Gestão Estratégica, Gestão de Mercadológica, entre muitas outras, as quais poderiam ser consideradas programas de pesquisa progressivos na área. 


\section{Objeto de estudo da Administração}

Autores como Ulrich (1990), que escrevem sobre a Administração como ciência, afirmam que, para que exista uma ciência, tem que existir o objeto. É importante, não obstante, considerar a afirmação de Bruyne et al. (1991), que indica que é por meio do domínio do objeto que a ciência vive o mundo real, ou seja, esse universo de coisas e de significações que nos é revelado na percepção. Segundo Bruyne et al. (1991), é precisamente partindo da construção do objeto que se poderá captar o aspecto dinâmico do procedimento científico.

Há questionamentos sobre o objeto de estudo da Administração e que este não seria bem definido, pois consideram que a área não possui um objeto definido como uma entidade empírica e factível; mas é justamente o contrário: a Administração seria um procedimento usado para se alcançar um determinado objetivo (MARQUES; LANA, 2004). Com relação à afirmação de Ulrich (1990) de que para existir uma ciência é necessária a existência do objeto dessa ciência, nos baseamos em Albach (1993) para afirmar que o objeto da administração é a "firma", ou seja, a empresa, mas não somente o aspecto de dar forma à empresa (estrutura), senão também toda a problemática relacionada como processo de condução da empresa (estratégia e relações internas e externas) e seu desenvolvimento, compreendendo os aspectos culturais e a evolução no tempo. O objeto da Administração é a própria empresa e toda a problemática que é imposta por todos os elementos, assim como pela integração desses elementos (áreas funcionais, tecnologia, recursos, ambiente, pessoal etc.). As diversas escolas da Administração (ou os paradigmas) surgiram como propósito de conhecer a empresa e tentar resolver os problemas que apresenta. A cada nova classe de problemas é provável que apareçam novas ideais e métodos de soluções, tudo com a finalidade de garantir a continuidade da empresa.

\section{Considerações finais}

Neste ensaio, objetivou-se estimular a reflexão e o debate acerca da cientificidade da Administração e seus critérios de demarcação científica encontrados nas obras dos filósofos da ciência Karl Popper, Thomas Kuhn e Imre Lakatos. Evidentemente, não se buscou, aqui, colocar de maneira definitiva a cientificidade da Administração, mas levantar alguns argumentos, apresentados anteriormente, que pudessem indicar o caminho científico da área. Grande parte da academia questiona a cientificidade da Administração, pois, para esses acadêmicos, a existência de múltiplos paradigmas e teorias poderiam dificultar o entendimento sobre a área (TAFFAREL; SILVA, 2013; CAMPANARIO; CHAGAS JR.; RUIZ, 2012; WALTER; ROCHA, 2011; DAMKE; WALTER; SILVA; 2010).

Em relação aos filósofos supracitados, vale ressaltar que Popper $(1968 ; 1975)$ busca justificar que o modo de fazer ciência é um processo racional e que busca a criação de um conhecimento objetivo. Segundo Kuhn (1975), porém, nem sempre é isso que ocorre junto à comunidade científica de uma determinada área, pois se deve analisar que também na dinâmica da comunidade científica há atividades que são baseadas em questões que seguem algum viés, provocadas por certo compromisso do pesquisador (seja com a tradição, seja com a própria comunidade). Além disso, enfatiza Kuhn (1975) sobre a natureza da mudança de paradigma, muitas vezes ocorre não como resultado de um processo racional, mas, sim, como um processo de conversão, introduzindo no campo da ciência uma dimensão irracional e, por que não dizer, também metafísica. De acordo com Kuhn (1975), essas características são elementos essenciais para o sucesso da atividade científica, pois sem eles não há um modo para a pesquisa científica proceder de forma eficaz. Já Lakatos (1979), embora parta dos pressupostos de Popper (1968), sempre busca um melhor desenvolvimento das ideias para transpor as críticas feitas por Kuhn.

Para Lakatos (1979), só poderia ser considerada ciência uma metodologia que poderia ser falseada e aprimorada para gerar uma nova metodologia, vindo desse fato a expressão "falseacionismo sofisticado". Dessa forma, o programa de pesquisa lakatosiano se tornou uma estrutura que fornece um guia para futuras pesquisas, tanto de uma maneira positiva como negativa. A ideia desse novo programa de pesquisa científica foi elaborada por Lakatos (1979) baseada na evolução de outras teorias que modificaram o método científico e trouxeram vários avanços científicos, como a descoberta de Netuno e a construção do telescópio, que só 
foram possíveis pela insistência em um núcleo irrefutável (heurística negativa), apenas sugerindo outras hipóteses (heurística positiva).

Portanto, deve-se refletir sobre algumas questões relativas a esses temas. Primeiramente, a ciência não possui um método objetivo e seguro para ser feita, pois o próprio método é uma evolução de um modo anterior de se fazer (LAKATOS, 1979). As teorias em que os métodos científicos se baseiam não são isentas de erros e isso influencia na descoberta de evidências que falsificam teorias, mas que não chegam a modificálas, mas as fazem evoluir, como mostram os estudos de Lakatos (1979). Além do mais, a história da ciência é também a história dos programas em concorrência. As chamadas "Revoluções Científicas" constituemse, na verdade, como um processo racional de superação de um programa por outro. Primeiramente, analisando-se de uma perspectiva desfavorável, muitos se referem à Administração como uma área que se forma em relações com outras disciplinas (KUHN, 1975). Isto faz com que a área seja considerada apenas um conjunto de ferramentas para formar uma "Teoria da Decisão", não a considerando uma Ciência Social Aplicada. Obviamente, é possível afirmar que a Administração não configura uma "ciência" que se utiliza apenas de disciplinas de suas respectivas áreas, assim como a Economia (que sempre é utilizada como exemplo de Ciência Social com um critério de demarcação bem definido), também não se classifica como "ciência" de disciplinas específicas de sua área.

Em segundo lugar, deve-se refletir que, tanto nas Ciências Exatas e Naturais como nas Ciências Sociais (ditas 'aplicadas' ou não), os problemas precedem as ações. Nesse sentido, a Administração não é diferente. Nos estudos em Administração o que se estuda é o conjunto de fatores e variáveis que explicam os fenômenos organizacionais, como o comportamento humano e sua influência sobre as organizações, assim como as interações entre as organizações, para gerar teorias (ou modelos) que serão futuramente utilizados pelos praticantes (gestores de organizações).

Finalizando nossa análise, reafirmamos nossa opinião de que a Administração é uma ciência real prática. Baseamos nossa opinião na verificação dos diversos critérios de demarcação da ciência, apresentados neste artigo, tal como os de Popper, Kuhn e Lakatos. Segundo esses critérios, a Administração cumpre os requisitos para ser considerada uma ciência, tal como argumentado anteriormente, pois possui um objeto de estudo, ainda em processo de formação, o que faz que a área seja uma ciência nova. AAdministração é uma ciência prática, pois está relacionada com a resolução de problemas da realidade, mas não somente se ocupa com a solução de problemas, senão também aumenta seu conhecimento de seu objeto e da realidade. A Administração possui ou aplica recursos metodológicos que obedecem a uma lógica da descoberta e da justificação, o que envolve tanto o produto da ciência como seu processo. Por tudo isso, sem termos a pretensão de finalizar qualquer debate sobre um tema tão complexo, consideramos que a Administração de empresas é uma ciência.

\section{Referências}

AKTOUF, O. Ensino de Administração: por uma pedagogia para a mudança. Organizações \& Sociedade, v.12, n.35, p.151-159 - out./dez. 2005.

ALBACH, H. La economia de la empresa como ciencia. Alcalá: Universidad de Alcalá,1993.

BERNARDES, C. MARCONDES, R. C. Teoria geral da administração: gerenciando organizações. São Paulo: Saraiva, 2006.

BUNGE, M. Ciência e desenvolvimento. Belo Horizonte: Itatiaia: São Paulo: Ed. Universidade de São Paulo, 1980.

BURREL, G.; MORGAN, G. Sociological paradigms and organizational analysis. London: Heinemann, 1979.

BUSANELO, E. C., SCHLICKMANN, R. Contribuições da Critical Management Studies (CMS) para a epistemologia da Administração. VI Encontro de Estudos Organizacionais da ANPAD. Florianópolis, 2010. 
CAMPANARIO, M. A.; CHAGAS JR., M. F.; RUIZ, M. S. O modelo de Karl Popper sob a ótica das Ciências Sociais Aplicadas. RCA - Revista de Ciências da Administração, v. 14, n. 32, p. 124-140, abr. 2012.

CAPRA, F. O ponto de mutação: a ciência, a sociedade e a cultura emergente. São Paulo: Editora Cultrix, 1987.

CHALMERS, A. F. O que é ciência, afinal? São Paulo: Brasiliense, 1993.

CLEGG, S. R.; HARDY, C. Introdução: organização e estudos organizacionais. In: CLEGG, S.; HARDY, C.; NORD, W. (Org.). Handbook de estudos organizacionais. São Paulo: Atlas, 2010 (v. 1). p. 29-58.

DAMKE, E.; WALTER, S. A.; SILVA, E. D. A Administração é uma Ciência? Reflexões Epistemológicas acerca de sua Cientificidade. Revista de Ciências da Administração, v. 12, n. 28, p. 127-146, set./dez. 2010.

DUFOUR, B. Management is not a science. en Hochschuschulnarichten Aus Der Wissenschaftlichen Hochschule Fuer Unternehmensfuehrung Koblenz, p. 69- 72, 1992.FIGUEIRAS, Eugenio Recio.

Metodología de las Ciências Sociales. Revista española de la opinión pública. No. 34 (Oct. - Dec., 1973), pp. 119-151.

GUTENBERG, E. Zur Theorie der Unternehmung: Schriften und Reden von Erich Gutenberg; H. Albach (ed.); Wiesbaden, 1989.

JENSEN,Hans S. (The Manifold of Paradigms: On what it means to use science and do research) - en el material de la asignatura de Fundamentos de la ciência del management (año lectivo 1998/1999).

KÖHLER, R. Research Methods in Business Administration, in: Handbook of German Business Management (Hrsg.: E. Grochla, E. Gaugler et al.), Vol. 2, Stuttgart - Berlin - Heidelberg et al. 1990, Sp. 2134-2149.

KUHN, Thomas S. A estrutura das revoluções científicas. 7. ed. São Paulo: Perspectiva, 2003.

LABORIT, H. Deus não joga dados. São Paulo: Trajetória Cultural. 1988.

LAKATOS, I.; MUSGRAVE, A. A crítica e o desenvolvimento do conhecimento. São Paulo: Editora da Universidade de São Paulo, 1979.

LEMOS, D. C.; BAZZO, W. A. Administração como uma ciência social aplicada: integrando ciência, tecnologia e sociedade no ensino de Administração. RPCA - Revista Pensamento Contemporâneo em Administração, v. 5, n. 3, p. 1-14. set./dez. 2011.

LEVIE, J. Ontological paradigms in management literature. Research paradigms in business studies. eds. T Elfring, HS Jensen, and A Money, 79-92. Copenhagen: Handelshøjskolens Forslag. 1995.

MARQUES, S. C. M.; LANA, R. C. Das técnicas e valores: características epistemológicas da Administração. Gestão e Conhecimento, v.1, n.0, jul. /nov. 2004.

MATTOS, P. L. C. L. "Administração é ciência ou arte?" O que podemos aprender com este malentendido? RAE - Revista de Administração de Empresas, São Paulo, v. 49, n. 3, p. 349-360, jul./set. 2009.

MATTOS, P. L. C. L. O Que diria Popper à literatura administrativa de mercado? RAE - Revista de Administração de Empresas. São Paulo, v. 43, n. 1, p. 60-69. jan./mar. 2003.

MINTZBERG, H. MBA? Não, obrigado: uma crítica sobre a gestão e o desenvolvimento de gerentes. Porto Alegre: Bookman, 2006.

MORGAN, Gareth. Paradigms, Metaphors, and Puzzle Solving in Organization Theory Source: Administrative Science Quarterly, Vol. 25, No. 4 (Dec., 1980), pp. 605-622.

POPPER, K. R. Conhecimento objetivo: uma abordagem evolucionária. Editora da Universidade de São Paulo: São Paulo, 1975. 
POPPER, K. R. The logic of scientific discovery. 5. ed. London: Hitchison, 1968.

SERVA, M. Epistemologia e sociologia da ciência da Administração. Cadernos EBAPE.BR, v. 11, n. 4, p.500-502, dez. 2013.

TAFFAREL, M; SILVA, E. D. A cientificidade da administração emdebate. RAD - Revista Administração em Diálogo, v.15, n.3, p. 33-56, 2013.

ULRICH, HANS. Subject matter of Business Administration. En Handbook of German Business Management, G.B.M Verlang C E Poeschel. Springer Berlin, 1990.

WALTER, S. A.; ROCHA, D. T. A contribuição de Thomas Kuhn para a produção científica em Administração. RCA - Revista de Ciências da Administração. v. 13, n. 30, p. 11-38, maio/ago 2011 WEBER, M. Ciência e política: duas vocações. São Paulo: Martin Claret, 2006.

Wöhe, Günter. Business Administration: Present Theoretical Approaches, in: Handbook of German Business Management (Hrsg.: E. Grochla, E. Gaugler et al.), Vol. 2, Stuttgart - Berlin - Heidelberg et al. 1990, Sp. 270-291.

Submetido em: 30/06/2019

Aceito em: 30/07/2019 